\title{
TRACKING OF KARST CONTAMINATION USING ALTERNATIVE MONITORING STRATEGIES: HIDDEN RIVER CAVE KENTUCKY
}

\section{Caren Raedts}

Department of Geography, Western University, 1151 Richmond Street, London, ON N6A5C2, Canada, craedts@uwo.ca

\author{
Chris Smart \\ Department of Geography, Western University, 1151 Richmond Street, London, ON N6A5C2, Canada, \\ csmart@uwo.ca
}

\begin{abstract}
Karst groundwater contamination presents great challenges for efficient monitoring because of rapid, discrete transport and the diversity of contaminants. Here a low cost approach is described and applied to Hidden River Cave, Kentucky, where a long history of contamination has been experienced. Local knowledge was acquired through informal interviews and coupled with observations of contaminant residues, faunal distributions and fluorescence spectra in the cave. The resulting patterns were interpreted using Google Earth and Street View to identify specific contaminant sources in the affected sub-catchment of the cave. Despite success in matching contaminant sources with the contamination history and pattern, the informal nature of the investigation renders it unacceptable as the basis for any intervention. But such low cost studies will be needed for the majority of contamination occurrences where financial resources are very limited. A radical revision of our adversarial approach to environmental management will be required for such a change to occur.
\end{abstract}

\section{Introduction}

\section{Alternative monitoring technologies}

Water contamination is a major karst hazard that presents great challenges for efficient monitoring (Gutierrez et al., 2014). Contamination can arise from a wide array of chemicals that may react, be released, sequestered, or transported through a variety of processes. This complexity must be resolved to comprehend, prevent and remediate the contamination. Yet a comprehensive understanding of water contamination requires a logistically impractical characterization of the composition, timing, and spatial distribution of contaminants. Agencies frequently focus resources on the detailed composition of contamination, rendering locational and temporal characteristics as lower priority. This analytical bias reflects legislation and a strong technical emphasis, in comparison with considerations of sampling. Consider the widely used binary contingency framework to categorize spatial (point and diffuse source) and temporal (acute and chronic release) characteristics. This is convenient, but provides little substantial insight in dealing with real world contamination. The result seems to be an expensive emphasis on handling and analytical protocol rather than a consideration of appropriate spatial and temporal sampling strategies. Here, an informal screening approach is taken to environmental monitoring, using a variety of qualitative and quantitative tools for a very low cost environmental appraisal.

Karst aquifers have presented peculiar difficulties for monitoring because rapid longitudinal transport makes detection and mapping of transient contamination challenging using monitoring wells. Yet complementary transverse dispersion of a much lower order may yield results consistent with porous medium models, confounding ready interpretation. As a result, practical groundwater models are yet to be widely accepted in karst investigations, or else porous medium models are used to over-ride a karst conceptual model. (Worthington \& Smart, 2012).

Fortunately, the drainage conduits in karst aquifers allow efficient groundwater tracing to be applied to resolve contaminant trajectories and catchment areas. Furthermore, conduits generally function as dendritic networks, at least under base flow conditions. This allows the utilization of springs or trunk conduits as monitoring sites that integrate the runoff from the upstream drainage area, much the same as surface water monitoring sites are used to characterize a catchment area (Quinlan et al., 1991). The limitation of this approach is that a contaminant source cannot be precisely located within the catchment area other than through sequential tracing and tracking-an expensive proposition.

Identifying the source of karst contaminants is feasible, but requires substantial resources if it is to be successful in litigation. This cost and uncertainty prevents resolution of many contamination problems, even egregious events. The proposition explored here integrates a wide 
spectrum of inexpensive monitoring strategies: the use of the mapped cave network and snapshot field observation and sampling, coupled with open access digital mapping (Google Earth and Street View) to tie contamination events to a surface land use. It is also assumed that cave biota (cave crayfish- Orconectes pellucidus) populations and kills will reflect recent acute contamination (Chapman, 1993), although the sensitivity, response and recovery dynamics are unknown. Furthermore, an emphasis is placed on narrative sources in the design of field sampling and the interpretation of results. The project was undertaken through annual college field excursions of a few hours duration from 2008-2014.

\section{Hidden River Cave}

Hidden River Cave lies under the town of Horse Cave, Hart Co. Kentucky, and is accessed through a collapsed sinkhole managed by the American Cave Museum. The cave consists of a dendritic network of canyons and collapsed domes (Figure 1). The main stream (East River) rises from rubble at the bottom of the entrance collapse and drains an area of $\sim 150 \mathrm{~km}^{2}$ based on dye tracing (Quinlan \& Rowe, 1977). A much smaller stream (South River) drains $\sim 8 \mathrm{~km}^{2}$, and has been explored up three main tributaries: Kneebuster, Lover's Lane, and Wheet River. The latter is the dominant source of the South River, but disappears under breakdown to re-emerge as the South River. Additional small tributaries and seeps enter this section of the cave and are presumed to link to numerous surface sinkholes, although none of these are known entrances. In addition, a number of poorly drained depressions in Horse Cave have been augmented by drilled drainage wells; casings of two of these are encountered in the cave passage.

Hidden River Cave has a rich history of exploitation as a tourist cave and hydro-power site, but also as a dump site (Veni et al., 2001). Raw sewage and untreated industrial waste (dairy and metal plating effluent) were discharged into a sinkhole at the extremity of the Lover's Lane tributary of the South River. These contaminants resulted in eutrophic, anoxic conditions, annihilating cave life and rendering the cave and the City of Horse cave foul and repellent (Quinlan \& Rowe, 1977). Fortunately, this degradation was publicized and remedied by the establishment of a regional sanitary sewer system in 1983, following which the cave ecology recovered and the cave could be reopened for tours.

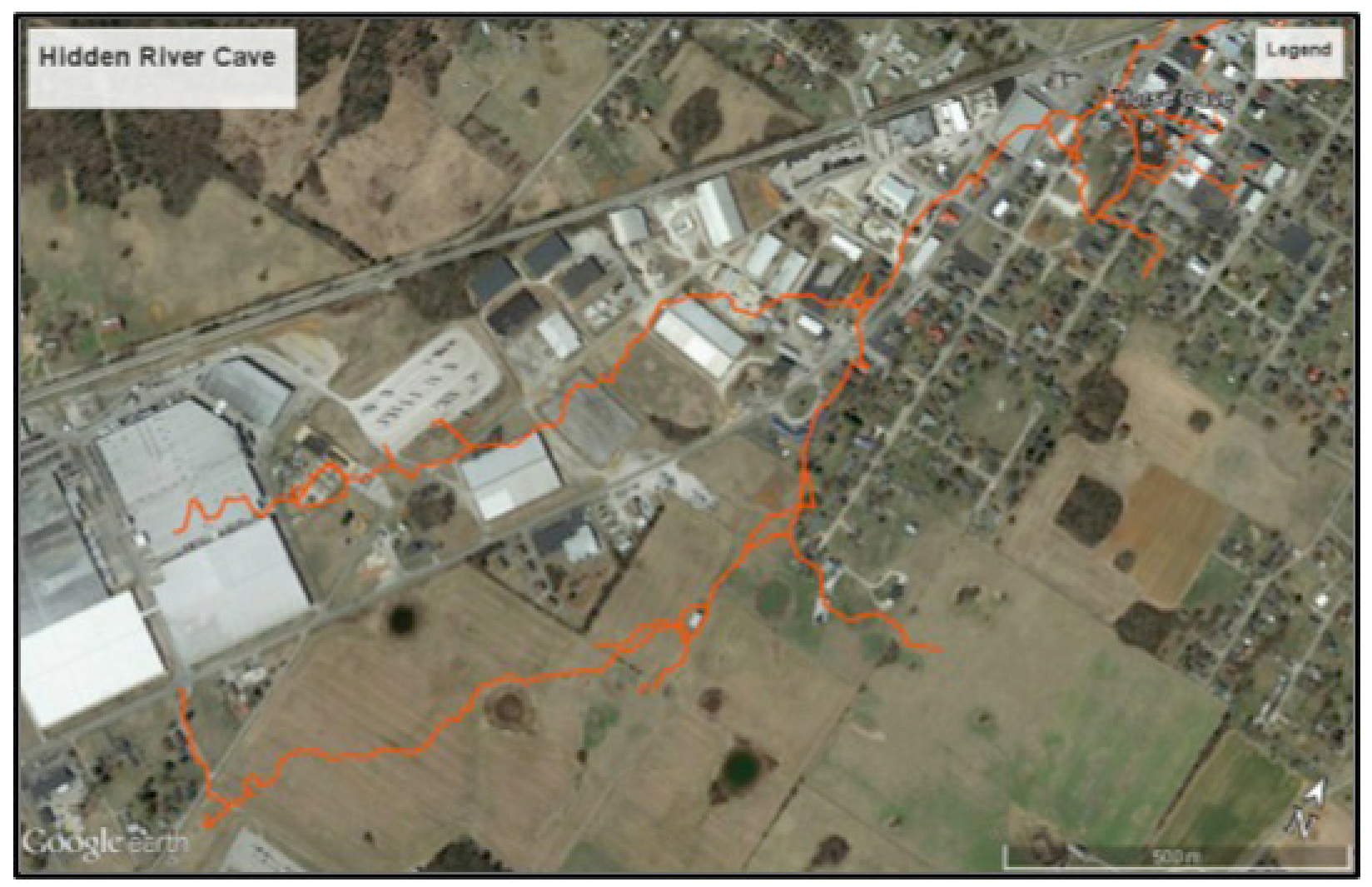

Figure 1. Line plot of Hidden River Cave overlain on Google Earth (March 2014) image. Main features in the cave and some surface features. 
Since the millennium, there has been substantial industrial development in the catchment area of the South River, contaminants have been encountered in the cave and periodic annihilation of the cave crayfish has occurred. But in the absence of any formal monitoring and recording, such episodes are generally narrative rather than scientific. Lack of funds and expertise has limited the documentation and action on these contamination events. A routine cave tour by a senior college class in 2008 initiated studies of the contamination that have continued annually to the present day.

\section{Monitoring}

From 2008, each year in September for one afternoon, a small student group has explored the South River -Wheet River section of Hidden River Cave. Informal discussions with the staff provided an idea of the contemporary crayfish numbers and any kills, contamination events perceived in the cave and possible surface origins and triggers. The number of living and dead cave crayfish occupying pools through the cave have been noted, along with descriptions of any detrital material.

Analysis of water samples for putative transient contaminants is prohibitively expensive because not only is the contaminant species unknown, but there may be little indication of which samples merit analysis. The notion of screening using surrogate water quality variables is long-established in karst hydrology. For example, electrical conductivity has been widely used as an inexpensive, continuous surrogate for total dissolved solids, ionic concentrations and even chemical equilibria (Meus et al., 2014). Electrical conductivity is readily measured, but is a relatively poor surrogate for groundwater contamination. A continuous record has been obtained from the East River from fall 2013-2014, but the complementary logger in the South River has yet to be recovered, so these results are not presented here.

Dye tracing literature has long dealt with "background fluorescence" as a nuisance (Smart \& Karunaratne 2002), but a wide range of environmental contaminants have expression in fluorescence. For example, fuels, raw sewage, road runoff and overland flow can all be revealed in the fluorescence spectrum, as can leaking treated water (Hartell et al., 2007; Mudarra, Andreo, \& Baker, 2010; Quiers et al., 2014.). However, none of these contaminants has a direct quantifiable fluorescence signature, and this indicates an empirical rather than analytical approach. In other words, there is no formal calibration for contaminants, although confidence can be gained using samples of known provenance or composition.
Water samples have been collected from cave streams, tributaries, pools and drips, and analyzed using a UVVIS Spectrofluorometer to obtain synchronous scans at $\Delta \lambda=20$ and $90 \mathrm{~nm}$ with $5 \mathrm{~nm}$ slit settings using a tap water blank and ambient fluorescent lighting for calibration. The raw scans were smoothed, normalized and standardized using the collective median for all samples at a given wavelength, and the median of a wavelength range for each sample, respectively. The resulting spectra show anomalies with respect to the sample ensemble for each year.

An inherent component of the contaminant narrative was putative contaminant sources. These sites were explored and documented, as time permitted, on the surface using a custom ArcGIS field collector application and through Google Earth and Street View.

\section{Monitoring results Narrative}

The initial modern era contamination event was by plastic injection molding stock pellets ("nurdles"), likely originating from Dart Containers, a packaging company with a plant adjacent to the former sewage treatment plant and a warehouse in the upper Wheet River area. A bark mulch contamination event was described in the Wheet River, with a postulated origin outside the catchment area. A variety of contaminants (liquid cement, tar, oil, soap, fuel) was described at the drainage well casing. A strong odor of chlorine was commonly encountered in the Waterfall Room, where a perennial cascade enters from the cave roof. Crayfish kills were not clearly linked to these events, but were interpreted to originate from the headwaters of the Wheet River where a condiments factory has a waste treatment facility.

\section{Residues in the cave}

Plastic nurdles were encountered embedded in mud on the cave wall, mostly downstream of the Lover's Lane tributary suggesting an origin from that tributary. Bark mulch residues were restricted to the main Wheet River. Crayfish exoskeleton fragments were found with some of the bark, having similar sediment transport properties. Soap, concrete, LNAPL and brown staining were observed at the drainage well. Chlorine odor was detected at the waterfall room. All these observations confirm the narrative descriptions. In addition, a few hundred ml DNAPL blob (Loop \& White, 2001) was observed in 2008 at the end of Kneebuster Crawl. The DNAPL appeared to have drained from an erosional scar in an adjacent sediment bank. A dead crayfish lying on the DNAPL was being consumed by a live crayfish. A small trickle in the wall of the cave downstream of the entrance 
was coated in a filamentous slime, presumably bacterial in composition.

\section{Cave Crayfish etc.}

The crayfish population varied considerably from year to year, but part of this variability will reflect changes in the diligence and skill of observation, illumination power and stream turbidity (The Wheet River is particularly muddy and permits a one-time survey moving upstream). A professional biotic survey has been undertaken in recent years (in prep.) generating superior data indicating under-recording in our surveys, but general consistency of distribution patterns.

The general trend has been for a gradual increase in Wheet River crayfish population since 2008, although in part this may reflect improved illumination and skill. Very few were encountered in Wheet River in 2008, with the exception of five or six individuals occupying a tributary stream. In 2009, this small cluster had expanded out into the main river, largely downstream, and were observed feeding in detritus, including crayfish fragments. In contrast, there has been a gradual decline in counts in the Kneebuster tributary.

Crayfish were occasionally encountered in ad hoc locations such as small inlets and isolated pools up to $5 \mathrm{~m}$ above stream level and well above flood lines. A small number of surface crayfish (Cambarus tenebrosus) were also encountered in the Wheet River. The implications of this are not known.

Blind cave fish (Typhlichthys subterraneus) were observed rarely in the Wheet River since 2013. Isopods were seldom evident, although numerous in an inlet tube downstream of the cave entrance. This suggests the cave ecosystem is still sub-optimum, either due to residual contamination or ongoing events.

The patterns observed indicate that cave crayfish are responsive to presumed contamination. They are surprisingly mobile and therefore able to migrate to and from refugia, such as clean tributaries. They are not restricted to the saturated zone. In addition to avoiding contaminated areas, the crayfish are drawn to rich food sources, including their own species. Depending on the contaminant, this may perpetuate mortality.

\section{Fluorescence monitoring}

Replicate analyses, replicate samples and longitudinal samples in particular stream reaches showed very consistent spectra. Care had to be taken to avoid sediment contamination of samples as even small inclusions resulted in anomalous spectra. Disposable plastic $5 \mathrm{ml}$ pi- pettes proved to be the most efficient way of collecting a clean sample, avoiding inconsistency from collecting LNAPLs by dip sampling and allowed sampling from quite shallow pools. The marked fluorescence anomalies arising from floating product and sediment elution suggest quite complicated migration and sequestration of contaminants (Vesper \& White, 2004; Vesper \& White, 2006). However, the results are difficult to replicate and are a source of variance, extraneous to the neutral density, aqueous phase population drawn on for statistical analysis.

Normalized fluorescence spectra (e.g. Figure 2) were analyzed based on broad spectrum ranking, as well as particular peaks indicative of dyes, sewage and fuels. The broad spectrum fluorescence shows distinctive clustering for particular streams, depending on prevailing runoff conditions, so that the East River may or may not have higher levels than the South River in a given year. Figure 3 shows the ranked 350-450 nm normalized fluorescence at $\Delta \lambda=90 \mathrm{~nm}$, highlighting the clustering of broad fluorescence and dissolved organic matter in particular sub-catchments (Birdwell \& Engel, 2010). (The synchronous scan offset and exact waveband does not materially affect this outcome, although year-to-year order is highly variable).

More systematically, the upstream Wheet River has lower contamination than the downstream South River, although it is the dominant water source. An inconsistent variety of short wavelength emitters (typically fuels and lubricants) have been detected in seeps and drips in the breakdown section between the Wheet River and South River. Particularly marked concentrations appear in drips adjacent to the injection well casing and a large stalagmite. There is clearly contamination of this sector of the cave, although it does not exhibit consistent spectral form, indicating either a variety of contaminants, or differential transport and degradation (e.g. volatilization) of the various components through different tracer routes.

Small perennial cascades enter the cave at the Waterfall Room and adjacent Board Room, often with a distinctive chlorine odor that may indicate treated drinking water, possibly accounting for the perennial flow even after sustained droughts. Spectra from the Waterfall show very low broad fluorescence, a characteristic of mains water. Perplexingly, the waterfall room spectrum shows a distinctive $515 \mathrm{~nm}$ peak of comparable magnitude every year from 2008-2014. This peak is characteristic of the common tracer dye uranine (sodium fluorescein). The consistent level over many years suggests that this contaminant is not a tracer dye that would be expected to exhibit a declining concentration over time. Its as- 


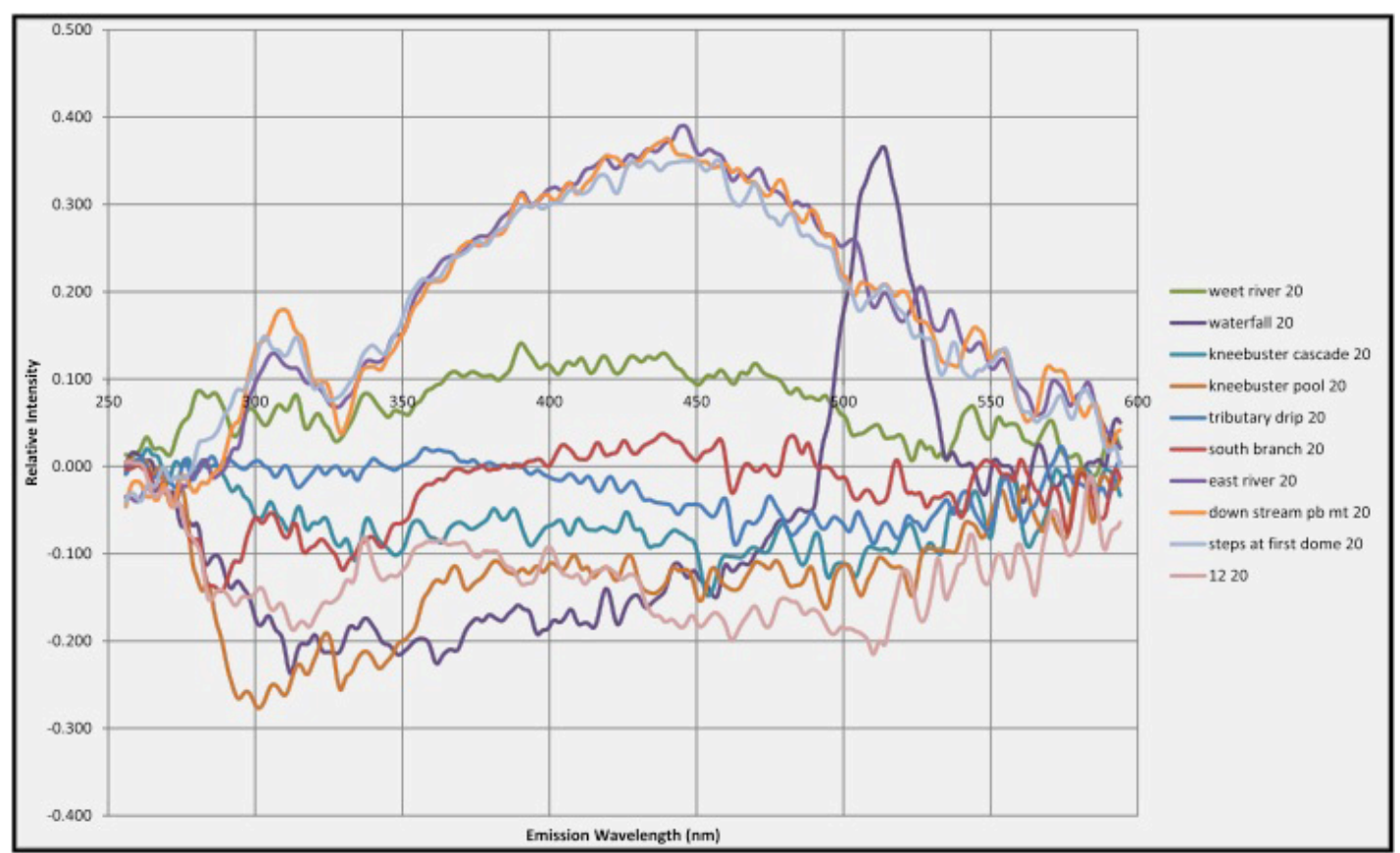

Figure 2. Example normalized fluorescence spectra $(\Delta \lambda=20 \mathrm{~nm})$ for 2013 showing interpretation of the spectral anomalies.

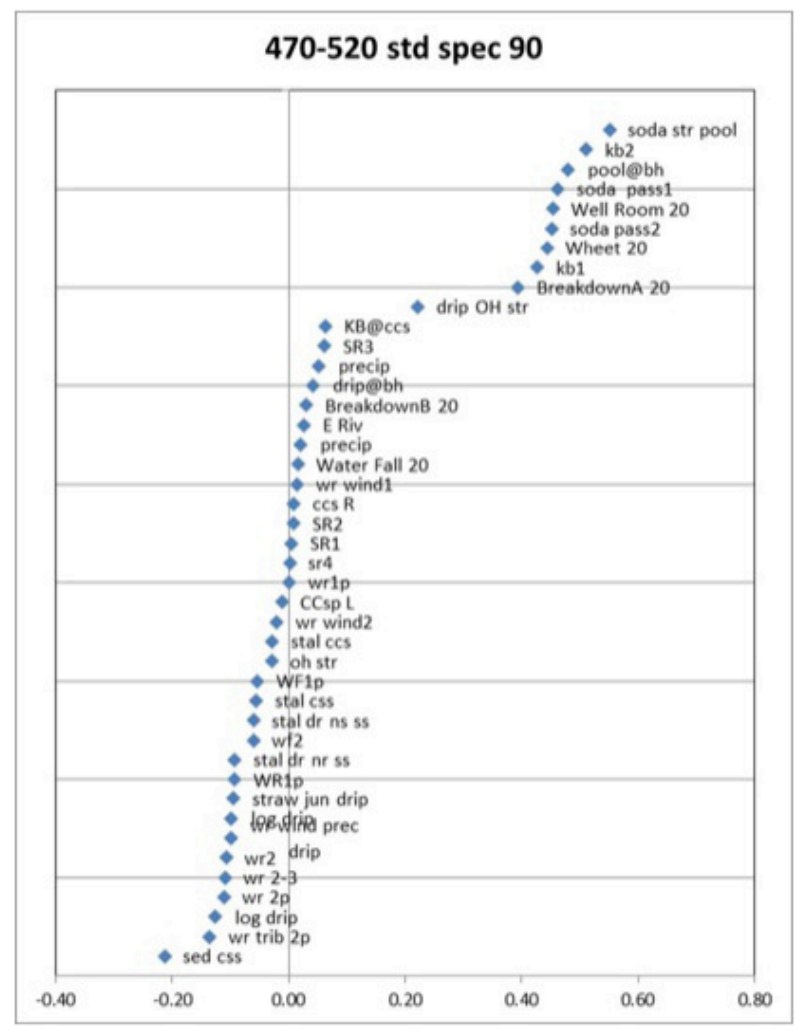

Figure 3. Rank ordered 2013 fluorescence samples for broad organic composition $(\Delta \lambda=90 \mathrm{~nm})$ showing distinctive clustering and higher readings in the Wheet-South River samples. sociation with mains water suggests an industrial source, possibly a garage or car wash where uranine stained antifreeze is being disposed. However, the invariant concentration suggests a steady release of tracer for which there is no obvious release mechanism.

The small slimy trickle downstream of the entrance shows a distinctive and consistent $435 \mathrm{~nm}$ peak, typical of optical brighteners in raw domestic sewage (Hartell et al., 2007).

\section{Summary and putative sources}

The patterns of crayfish numbers and contaminants are poorly correlated, or may be coincidental. For example, the bark mulch does not appear to have been sufficient to eradicate crayfish from the Wheet River, although it does clearly indicate a garden center as a putative source. The plastic beads are almost certainly from a plastics production facility. The general contamination in the breakdown area near the drainage wells suggests a construction or trucking operation. Uranine can be tentatively derived from a garage or car wash. Chlorination and low fluorescence indicates a mains water leak or disposal of consumed water by general runoff. Raw sewage indicates a poorly linked sanitary sewer. The DNAPLs observed in 2008 have not been encountered since. It is assumed that this contaminant is a legacy of the era of wholesale contamination that had been sequestered in cave sediments. The variety of fluorescent signatures 
arising from sediment elution suggests long-term sequestration of contaminants in the sediments (Vesper \& White, 2004). The subsequent task is to explore surface land use looking for the sources arising from narrative accounts and those indicated by the contaminant pattern in the cave.

\section{Surface Land-use}

Targeted field traverses have been undertaken from 2011-present, but overt site investigation tends to raise concern and even alarm in residents. Google Earth and Street View reconnaissance is much less confrontational, provides some historical perspective and allows insight into inaccessible or concealed areas, or activities not occurring at the time of field reconnaissance. A high-grade cave survey was geo-registered in Google Earth allowing for a direct comparison of surface land use, cave streams, and subsurface contamination.

\section{Google Earth}

High quality satellite imagery allows mapping of major industrial installations and waste management facilities. It is not always easy to categorically identify the indus- trial activity, and certainly Google Earth is not suited to detect acute contamination events given the infrequent imagery. Furthermore, the topographic rendering in Google Earth is not particularly accurate, and should only loosely be employed to define sinkhole catchments.

The regional sewage treatment facility (the origin of former contamination) is clearly visible. Immediately adjacent is a set of stock supply hoppers for Dart Container. Knowing that the plastic beads are typically stored in such hoppers, and that the adjacent sinkhole connects directly to the cave, it can be hypothesized that a spill at the site resulted in transport of plastic beads into the Lover's Lane tributary of the South River. (No stream has been detected in or emerging from the Lover's Lane tributary, but a link is inferred from past pollution history). A nearby Garden Center showed mulch bins adjacent to sinkholes near the Wheet River headwaters.

The locale of the condiments factory can be seen first developing in 2003, with a major waste treatment installation in 2006. Some major reconstruction and erosion control is documented in 2010, and a new fermenta-

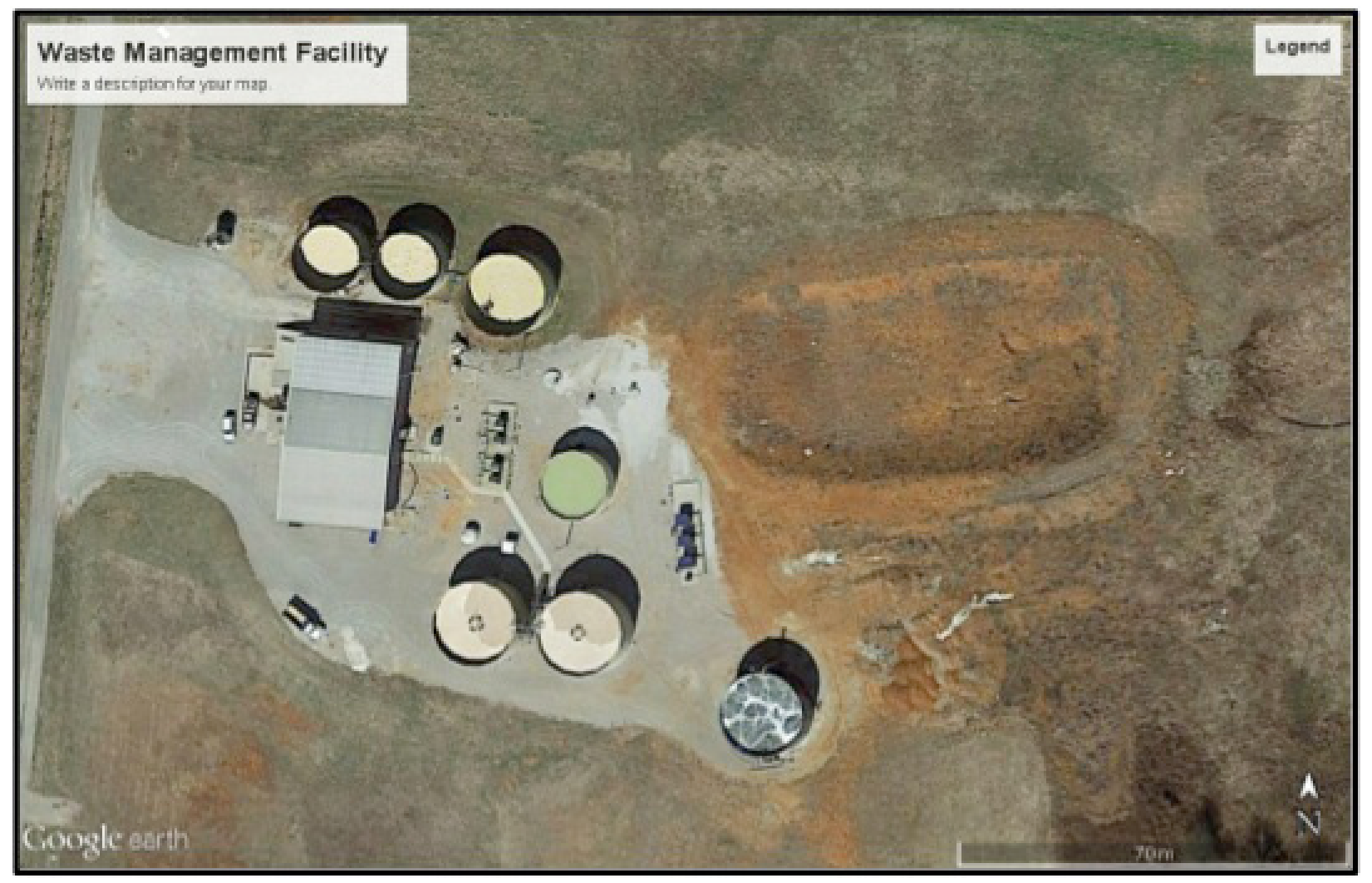

Figure 4. Google Earth Image March 2014. The condiments factory waste management facility and lagoon. The blue line indicates the overflow pipe orientation with outlet in a sinkhole feeding Hidden River Cave. 
tion tank and waste lagoon appears in 2014. (Figure 4). Other land use is more tentative and required review in Street View for confirmation.

\section{Street View}

Even minor backstreets of Horse Cave have been faithfully recorded in Street View, although private industrial areas are not mapped. Efforts were concentrated on the contaminated area around the drainage well, assuming a fairly direct passage of surface contamination into the underlying cave, or its inferred tributaries.

The garden center postulated to have generated the mulch contamination events indicates runoff may have been directed towards a number of sinkholes in the headwaters of the Wheet River. Numerous small and larger industrial installations occur over the contaminated section of cave. A car wash was inspected showing runoff entering directly into a storm drain in the major depression above the cave. (Although topography is not necessarily a guide to storm water runoff in urban areas, there does not seem to be much storm water management in Horse Cave, other than draining ponded water into the subsurface through injection wells). There is also a small garage, a rather disordered recycling center, and a fuel transfer depot/ gas station a little further away.

Narrative descriptions and field inspection (see below) identified a primary candidate drainage well adjacent to a carpentry shop, an unlikely source of contamination. However, immediately to the west of the injection well is a pre-mix concrete depot providing a source for the diverse contaminants encountered in the cave (fuel, lubricants, cement; Figure 5). Street View reveals the loading areas being hosed down with runoff draining directly to the drainage well, despite an apparent settlement tank on the site. Street View imagery shows a large dump truck loading at the food processing waste facility, suggesting solids removal.

\section{Field reconnaissance}

Field investigations were directed by hypotheses raised using Google Earth and Street View, but constrained by concerns over trespass and possible alarm. For example, it was not possible to look for residues of plastic beads around the postulated sink point because it was not accessible. However, at the garden center traces of mulch clearly indicated transport into a sinkhole south east of

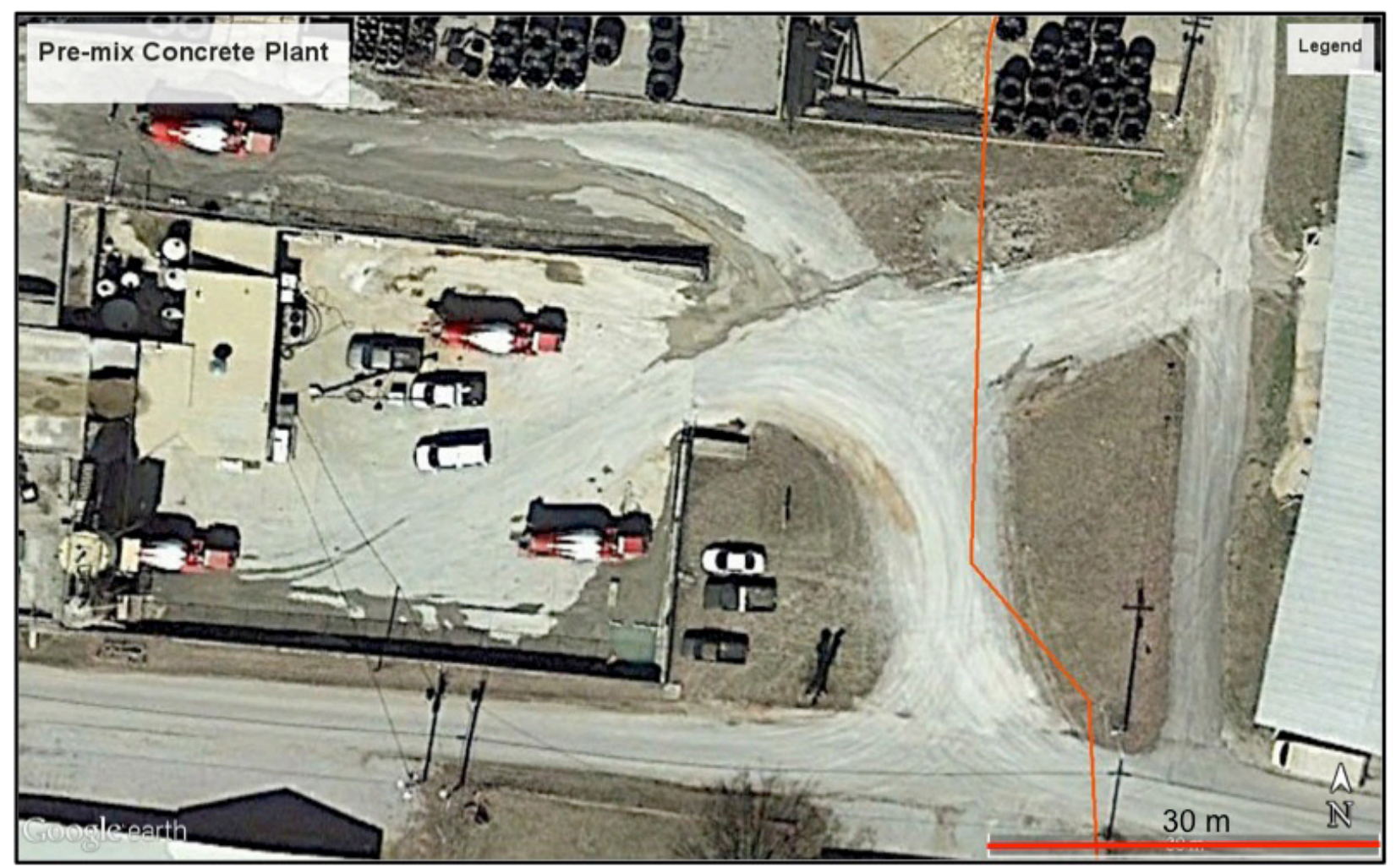

Figure 5. Google Earth Image March 2014. Premix concrete plant in Horse Cave. Runoff from the site follows the purple line that terminates at an open drainage well. The orange line represented the underlying cave passage, suggesting $\sim 25 \mathrm{~m}$ mis-registration. 
the storage bin. Any spills from the equipment maintenance area would also enter this sinkhole, feeding directly into the Wheet River.

A number of drainage wells and sink points were located in depressions over the cave, but uncertainties remains as to which feed directly into the cave. The drainage well receiving runoff from the pre-mix concrete facility showed contaminated runoff from pressure washing on the forecourt, off the site, through swales and into the drainage well. The on-site settling tank was stagnant and not utilized.

The condiment factory had extensively re-engineered the surroundings to direct storm water into sinkholes. In 2011, a sinkhole immediately north of the waste management facility was undergoing extensive modification. A collapse feature had developed in the floor of the sinkhole. By 2014 a large retention pond ( $~ 0.2$ ha) had been created at this site (Figure 5).

However an outflow pipe limited the retained depth to a maximum of $\sim 1 \mathrm{~m}$, with the outflow being directed to a major sinkhole. Some erosion of the floor makes its ultimate integrity uncertain. There was no evidence of waste being dumped into the lagoon, suggesting that it may be an emergency retention pond, to contain accidental spills or excess liquids. It is not clear what the ultimate fate of the treated waste might be. Narrative accounts describe tankers hauling waste to a landfill site. The fate of surplus liquids is not known.

\section{Contaminants \& Land Use Practices}

The suite of contaminants inferred from narratives and monitoring can be surprisingly well-tracked to normal surface land use practices and accidents that arise through day-to-day operations in an industrial park. This is surprising as the contaminant events tracked are all acute point source events- the least likely to be captured by annual snapshot surveys. Only those events leaving clear residues, or surface evidence, have been identified. It is likely that the cave is actually exposed to many more events that elude detection. Such events may arise from contamination events resulting from the remobilization of contaminants sequestered in cave sediments.

Most of the acute contaminants inferred could be removed by the adoption of best management practices such as runoff capture and treatment, for instance oil \& grit separation. The condiment waste source appears to have already made moves in this direction.

The chronic contamination by sewage and uranine dye have not been sourced, although in principle they should be more readily tracked. The perennial uranine source is not readily interpreted, so the release process remains a mystery. The sewage detected indicates a source that is so widespread, that it is impossible to identify a precise origin.

The success in matching contaminant sources to the immediately subjacent cave suggests that routing through the unsaturated zone is vertical through the respective sinkhole or drainage well into the cave network. The presence of coarse particulates indicates discrete openings of at least $10 \mathrm{~cm}$ aperture. The contaminants entering the cave from the injection well are encountered outside the well casing, suggesting that the installation is dysfunctional.

There has been no follow-up on any of these contamination sources and events. This reflects the challenges of environmental protection against a background of industrial decline and stressed resources.

None of the evidence presented here would be acceptable if taken to litigation, as it lacks the formal scientific rigor required. It would be relatively straightforward to undertake local sink-cave stream traces to confirm linkages. But the evidence suggests that would just confirm the obvious. Tracking the individual contaminant sources using site-specific signatures would be prohibitively expensive, and probably ineffective for acute events. The apparent sequestration of contaminants in sediment may be a route around the latter barrier, but much more investigation would be required to work out the processes involved.

\section{Conclusions}

The contaminant history described and inferred here is likely representative (or even under-representative) of any developed landscape, and likely repeated in karst regions around the world. Spills, releases and disposal practices are so routine that they attract little attention.

This attitude has not been helped by the geographical partitioning of source and wastewater catchments, so that water consumption is independent of waste disposal practices. Only the most egregious contamination by large, financially robust entities warrants the necessary expenditure of efforts in monitoring and litigation. It is not clear that egregious contamination is necessarily the optimum target if environmental conservation is a priority. Persistent minor contamination may be more harmful.

Here, it has been shown that a fairly comprehensive, yet legally inadmissible investigation has identified a num- 
ber of contaminant sources that could be readily ameliorated, likely for far less than the cost of litigation. The foundation of this work lies in the social sciences- utilizing informal interview techniques to establish a focus for subsequent field monitoring. The field monitoring is also open ended, focusing on mapping rather than rigorous compositional analysis. The techniques are largely qualitative and yet have led to a valuable characterization of contamination at little cost. It is perhaps time that we managed our environment more through a comprehensive understanding rather than an adversarial review scrambling for scientific superiority.

More fundamentally, this study confirms that karst environments are vulnerable to routine contamination, and the damage is likely rapid and profound. However, despite possible sequestration of contaminants in sediments, the dendritic structure of karst drainage means rapid flushing with relatively little transverse dispersion. The drainage structure of karst aquifers therefore tends to preserve refugia. Furthermore cave biota are certainly preserved in the refugia and may even actively migrate into them when threatened by contamination.

\section{Acknowledgements}

The patience and hospitality of the American Cave Conservation Association at Hidden River Cave are greatly appreciated. Peggy Nims in particular has aided us is the cave and Dave Foster has facilitated our knowledge of the surface land use. The Cave Research Foundation and especially Pat Kambesis provided hospitality and knowledgeable advice. The students and assistants in Geography 3000 have eagerly participated in this project over many years. Field costs were covered by Western University.

\section{References}

Birdwell JE, Engel AS. 2010. Characterization of dissolved organic matter in cave and spring waters using UV-Vis absorbance and fluorescence spectroscopy. Organic Geochemistry 41 (3): 270280.

Chapman P. 1993. Caves \& Cave Life. Somerset, UK: HarperCollins.

Gutiérrez F, Parise H, DeWaele H, Jourde H. 2014. A review on natural and human-induced geohazards and impacts in karst. Earth-Science Reviews 138: 61-88

Hartel PG, McDonald JL, Gentit LC, Hemmings SNJ, Rodgers K, Smith KA, Belcher CN, Kuntz RL, Rivera-Torres Y, Otero E, Schroder EC. 2007. Improving fluorometry as a source tracking method to detect human fecal contamination. Estuaries and Coasts 30 (3): 551-561.
Loop CM, White WB. 2001. A conceptual model of DNAPL transport in karst groundwater basins. Groundwater 39 (1): 119-127.

Meus P, Moureaux P, Gaillez S, Flament J, Delloye F, Nix P. 2014. In situ monitoring of karst springs in Wallonia (southern Belgium). Environmental Earth Sciences 71 (2): 533-541.

Mudarra A, Andreo B., Baker A. 2010. Character-ization of dissolved organic matter in karst spring waters using intrinsic fluorescence: Relationship with infiltration processes. Science of the Total Environment 409 (18): 3448-3462.

Quiers M, Batiot-Guilhe C, Bicalho CC, Perrette Y, Seidel J-L, Exter S. 2014. Characterization of rapid infiltration flows and vulnerability in a karst aquifer using a decomposed fluorescence signal of dissolved organic matter. Environmental Earth Science 71 (2): 553-561.

Quinlan, JF, Rowe DR. 1977. Hydrology and water quality in the central Kentucky karst: Phase I. University of Kentucky, Water Resources Research Institute, Research Report 101, 93 p.

Quinlan JF, Smart PL, Schindel GM, Alexander EC, Edwards AJ, Smith AR. 1991. Recommended administrative/regulatory definition of karst aquifer, principles for classification of carbonate aquifers, and determination of optimum sampling frequency at Springs 573- 636 in Quinlan JF (Ed.) Third Conference on Hydrogeology, Ecology, Monitoring and Management of Ground Water in Karst Terranes US EPA and Assoc. Ground Water Scientists and Engineers Nashville TN, 807pp

Smart CC, Karunaratne KC. 2002. Characterisation of fluorescence background in dye tracing. Environmental Geology 42 (5): 492-498.

Veni G, DuChene H, Crawford NC, Groves CG, Huppert GN, Kastning EH, Olson R, Wheeler BJ. 2001. Living with karst: a fragile foundation. AGI Environmental Awareness Series 4, 66 p.

Vesper DJ, White WB. 2004. Spring and conduit sediments as storage reservoirs for heavy metals in karst aquifers. Environmental Geology 45 (4): 481493.

Vesper DJ, White WB. 2006. Comparative storm response of contaminants in a carbonate aquifer, Fort Campbell, Kentucky-Tennessee, Geological Society of America 267-274 In Harmon RS Wicks C (Eds.) Perspectives on karst geomorphology, hydrology and geochemistry. Geological Society of America Special Paper 404.

Worthington SRH, Smart CC. 2012. Triple porosity characteristics of a carbonate aquifer with bacterial contamination: Walkerton, Ontario, Canada. Journal of Hydrology 464-465: 517-527. 
